OPEN ACCESS

Edited by:

Dario Marchetti,

The Methodist Hospital Research

Institute, USA

Reviewed by:

Julie Valerie Decock,

Qatar Biomedical Research Institute,

Qatar

Zuheir Alshehabi,

Tishreen University, Syria

*Correspondence:

Tanja Fehm

tanja.fehm@med.uni-duesseldorf.de

Specialty section:

This article was submitted to Molecular and Cellular Oncology,

a section of the journal

Frontiers in Oncology

Received: 21 July 2016 Accepted: 18 November 2016 Published: 01 December 2016

Citation:

Banys-Paluchowski M, Krawczyk N and Fehm T (2016) Potential Role of Circulating Tumor Cell Detection and

Monitoring in Breast Cancer:

A Review of Current Evidence.

Front. Oncol. 6:255

doi: 10.3389/fonc. 2016.00255

\section{Potential Role of Circulating Tumor Cell Detection and Monitoring in Breast Cancer: A Review of Current Evidence}

\author{
Malgorzata Banys-Paluchowski', Natalia Krawczyk ${ }^{2}$ and Tanja Fehm ${ }^{2 *}$ \\ ${ }^{1}$ Department of Gynecology and Obstetrics, Marienkrankenhaus Hamburg, Hamburg, Germany, ${ }^{2}$ Department of Obstetrics \\ and Gynecology, University of Duesseldorf, Duesseldorf, Germany
}

The phenomenon of hematogenous tumor cell dissemination in patients with solid tumors has been extensively explored over the last decades. Breast cancer research investigated at first disseminated tumor cells in the bone marrow; however, the focus soon moved to circulating tumor cells (CTCs) in the peripheral blood as blood is easily accessible without an invasive procedure. The prognostic significance of CTC presence has been shown in large studies both in adjuvant and metastatic setting and commercially available detection assays have been evaluated for monitoring in clinical trials. Beyond detection and enumeration of CTCs, the characterization of single tumor cells may enhance our knowledge on disease progression and thus optimize treatment choices.

Keywords: breast cancer, disseminated tumor cell, circulating tumor cell, prognosis, biomarkers

\section{INTRODUCTION}

Breast cancer (BC) is the most common cancer type in women; its mortality is mostly due to distant metastatic growth. The phenomenon of hematogenous spread of single tumor cells shed from the primary tumor was first demonstrated in nineteenth century $(1,2)$. Tumor cells encountered at secondary homing sites, such as bone marrow $(\mathrm{BM})$ and peripheral blood (PB), are currently seen as surrogate marker for minimal residual disease (MRD) and precursors of distant metastasis. Detection of these cells and evaluation of their features can therefore contribute to our better understanding of the disease and improve therapy monitoring as well as personalized treatment options. The features of tumor cells and changes in the microenvironment at the homing site are the major subject of current translational research.

The prognostic significance of MRD in BC was first demonstrated in studies on disseminated tumor cells (DTCs) in BM. In 2005, a multicenter meta-analysis of BM aspirates collected from 4703 non-metastatic $\mathrm{BC}$ patients at time of diagnosis confirmed that DTC presence significantly correlates with shorter disease-free survival (DFS) and overall survival (3). Since venipuncture is more feasible than BM aspiration, subsequent studies shifted their focus to the easily accessible circulating tumor cells (CTCs) in the PB. The following review will address the current knowledge and future clinical possibilities of CTC evaluation in BC.

Abbreviations: BC, breast cancer; BCSS, breast cancer-specific survival; CTC, circulating tumor cell; DDFS, distant disease-free survival; DFS, disease-free survival; DMFS, distant metastasis-free survival; DTC, disseminated tumor cell; EpCAM, epithelial cell adhesion molecule; HER2, human epidermal growth factor receptor 2; MFS, metastasis-free survival; MRD, minimal residual disease; OS, overall survival; PFS, progression-free survival; RT-PCR, reverse transcription polymerase chain reaction. 


\section{CIRCULATING TUMOR CELLS IN EARLY BREAST CANCER}

The metastatic cascade consists of a series of steps that enable cells from the primary tumor to enter blood vessels, persist in initially hostile homing sites, and finally extravasate into the tissue of secondary organs. These steps may take place over a prolonged period of time, sometimes decades, involving mechanisms known as tumor cell dormancy (4). Due to improved screening, the majority of BC patients presents with disease localized to the breast and lymph nodes without evidence of distant metastasis. However, after completion of surgical treatment and adequate adjuvant therapy, a significant proportion of patients suffer from a distant recurrence, suggesting that the metastatic cascade had already been activated long before diagnosis.

Accumulating evidence suggests that the fate of tumor cells detached from the primary tumor is highly influenced not only by their own properties but also by microenvironment and immune system. In the blood stream and later in BM and distant organs, these rare cells are exposed to immune response of the host. It is widely accepted that a significant proportion of CTCs dies leaving only a small subpopulation capable of persistence, in a process generally referred to as "metastatic inefficiency" (5). Due to the rapid clearance of CTCs from the blood stream mediated by macrophages, monocytes, neutrophils, and natural killer cells, MRD is under continuous survival pressure to develop mechanisms enabling immune escape (6). Indeed, CTCs have been shown to overexpress proteins inhibiting the phagocytic activity of immune cells and downregulate major histocompatibility class I antigen expression (7-10). It has also been suggested that CTCs are able to stimulate the formation of premetastatic niche in secondary organs. In this context, a number of possible mechanisms have been proposed. Through expression of vascular signal proteins, CTCs can attract VEGFR-expressing hematopoetic stem cells that influence fibroblasts at the homing site, thus creating a favorable microenvironment for future metastatic growth (11). In an animal BC model, tumor cells were shown to induce production of chemokine ligands, especially CCL17 and CCL22, at secondary sites, leading to chemotaxis of both tumor and immune cells. A better knowledge of interactions between CTCs, the immune system and microenvironment could provide us with new therapeutic targets (12).

\section{Prognostic Significance of CTCs in Early BC}

Non-metastatic BC patients in whom tumor cells spread into the blood stream, i.e., who present with CTCs in their PB, are more likely to relapse in the course of disease (Table 1). To date, the largest clinical trial on the prognostic relevance of CTCs in early BC was launched by the German SUCCESS study group (EUDRA-CT No. 2005-000490-21, NCT02181101). Briefly, blood samples from over 2000 average-to-high-risk nonmetastatic BC patients before chemotherapy and nearly 1500 patients after chemotherapy were examined (13). Women with detectable CTCs before chemotherapy had significantly worse DFS and overall survival. In this trial, the relationship between CTC numbers and survival was evaluated in order to determine the optimal cutoff (no CTCs vs. $\geq 1 ; 0-1$ vs. $\geq 2 ; 0-4$ vs. $\geq 5$ CTCs in $30 \mathrm{ml}$ blood). For all cutoffs, a statistically significant impact on survival was shown. Women with five and more CTCs had highest risk for relapse. So far, the results from the SUCCESS trial were reported after a median follow-up of 36 months. Smaller trials with longer follow-up demonstrated the association between CTC presence and clinical outcome as well $(14,15)$. In a multicenter pooled analysis, Janni et al. confirmed CTC presence in early $\mathrm{BC}$ patients as an independent predictor of shorter disease-free, overall, BC-specific, and distant DFS (16). In the multivariate analysis, for all four survival endpoints alike, grading, tumor stage, nodal stage, hormone receptor status, and HER2 status were additional significant independent prognostic factors, while histologic type, menopausal status, neoadjuvant chemotherapy, and adjuvant chemotherapy were not significantly

TABLE 1 | Presence of CTCs and clinical outcome in non-metastatic BC patients.

\begin{tabular}{|c|c|c|c|c|c|c|}
\hline Reference & Patients & $\begin{array}{l}\text { Number of } \\
\text { patients }\end{array}$ & $\begin{array}{c}\text { CTC } \\
\text { positivity }\end{array}$ & Method & $\begin{array}{l}\text { Median } \\
\text { follow-up } \\
\text { (months) }\end{array}$ & $\begin{array}{l}\text { Association } \\
\text { between CTCs and } \\
\text { survival }\end{array}$ \\
\hline $\begin{array}{l}\text { Janni et al. (16) } \\
\text { pooled analysis }{ }^{a}\end{array}$ & Stages $|-|||$ & 3173 & 641 (20\%) & CellSearch & 63 & $\begin{array}{l}\text { DFS, DDFS, BCSS, } \\
\text { OS }\end{array}$ \\
\hline $\begin{array}{l}\text { Rack et al. (13), } \\
\text { SUCCESS trial }\end{array}$ & $\begin{array}{l}\text { Stages I-III, node-positive or high-risk node- } \\
\text { negative, all pts. received chemotherapy }\end{array}$ & 2026 & $435(21 \%)$ & CellSearch & 36 & $\begin{array}{l}\text { DFS, DDFS, BCSS, } \\
\text { OS }\end{array}$ \\
\hline Franken et al. (15) & Stages I-III & 404 & 76 (19\%) & CellSearch & 48 & DDFS, BCSS \\
\hline Lucci et al. (23) & Stages I-III & 302 & 73 (24\%) & CellSearch & 35 & DFS, OS \\
\hline $\begin{array}{l}\text { Bidard et al. (14), } \\
\text { REMAGUSO2 trial }\end{array}$ & $\begin{array}{l}\text { Neoadjuvant trial, Stages II and III, ineligible for } \\
\text { breast conserving surgery at diagnosis or high-risk }\end{array}$ & 95 & $22(23 \%)$ & CellSearch & 70 & DDFS, OS \\
\hline Molloy et al. (24) & Stages I and II & 733 & $58(8 \%)$ & $\begin{array}{l}\text { qRT-PCR (CK19, p1B, } \\
\text { EGP-2, PS2, and MmGl) }\end{array}$ & 91 & MFS, BCSS \\
\hline Ignatiadis et al. (17) & $\begin{array}{l}\text { Stages I-III, all pts. received adjuvant } \\
\text { chemotherapy }\end{array}$ & 444 & 181 (41\%) & RT-PCR (CK19) & 54 & DFS, OS \\
\hline Kuniyoshi et al. (25) & Stages I-III & 167 & & $\begin{array}{l}\text { RT-PCR (CK19, } \\
\text { c-erbB-2) }\end{array}$ & & n.s. \\
\hline Hwang et al. (19) & Stages I-IIla & 166 & 37 (22\%) & RT-PCR (CK20) & 100 & MFS, OS \\
\hline
\end{tabular}

n.s., not significant; BCSS, breast cancer-specific survival; DDFS, distant disease-free survival; DFS, disease-free survival; OS, overall survival; MFS, metastasis-free survival. aPooled analysis including data from five centers, some previously published as Ref. $(13,14,15,23)$. 
associated with disease recurrence or survival. Beyond that, the analysis added important new data on the prognostic value of CTCs in various BC subgroups. Most importantly, CTC presence did not significantly influence clinical outcome in low-risk patients with small node-negative tumors, suggesting that earlystage BCs could be treated successfully, independently of the presence of MRD in the blood. In contrast, the strong prognostic value of CTCs in high-risk patients underlines the future potential of CTCs to drive treatment decisions in this patient group. Furthermore, Janni et al. evaluated CTC detection in different molecular subgroups. Hypothetically, tumor cell dissemination patterns may differ according to the biological features of the disease. Indeed, CTC presence predicted survival in patients with tumors of the luminal subtype (i.e., hormone receptorpositive, including luminal B HER2-positive subtype) and with triple-negative tumors, but not in patients with HER2-positive, hormone receptor-negative tumors (16). Contrary to these results, Ignatiadis et al. found in a smaller study no association between CTC presence and prognosis in patients with luminal tumors, while CTC status was highly predictive of survival in the triple-negative and HER2-subtype $(17,18)$. Similar findings were reported by others (19-21). One aspect that needs to be taken into account is a relatively short follow-up of the available studies; so far, none of the abovementioned trials reported a follow-up longer than 100 months. Especially in case of hormone receptor-positive $\mathrm{BC}$, this might be insufficient to fully assess the clinical relevance of CTC presence as patients with luminal tumors are more at risk for a late relapse compared to those with more aggressive tumor subtypes (22).

The ability to assess tumor subtypes has been one of the mile stones toward personalized oncological treatment. In this context, considerable efforts have been undertaken to characterize the phenotype of CTCs and explore potential clinical applications beyond mere enumeration of tumor cells. It has been shown that expression profiles of CTCs do not correlate with the subtype of the corresponding primary tumor (26). However, while the presence of CTCs has been confirmed as an important predictor of worse survival in large trials, evidence regarding prognostic relevance of specific subtypes of CTCs in early BC is scarce. Wulfing et al. assessed the HER2 status of CTCs in a small cohort of 35 stages I-III BC patients and reported a significant association between positive HER2 status and shorter DFS and overall survival (27).

The relationship between DTCs in BM and CTCs in PB has been explored in a number of studies. While both DTCs and CTCs have been shown to predict clinical outcome with level I evidence $(3,16)$, only a few studies assessed both markers in patients with primary BC. The correlation between CTC and DTC positivity seems weak, ranging from 55 to $76 \%$, depending on the patient population and the method used (28-31). Which "homing site" is better suited for survival prediction remains unclear; while several studies found a stronger correlation between DTC presence and clinical outcome, others provided results in favor of CTCs. The major advantage of blood-based detection is the simplicity of blood sampling in comparison to BM biopsy. Since the procedure is non-invasive, serial measurements are possible.

\section{CTCs as a Therapy Monitoring Tool in Early BC}

Breast cancer patients in whom MRD in the BM persist beyond adjuvant chemotherapy are more likely to be diagnosed with a subsequent relapse (32). Evidence from CTC-based clinical trials showed that persistence of CTCs in the blood is associated with worse clinical outcome as well (Table 2). The SUCCESS trial demonstrated that CTC persistence correlates with shorter recurrence-free and overall survival (13). When both prechemotherapy and postchemotherapy CTC status was considered,

TABLE 2 | Presence of persistent CTCs and clinical outcome in non-metastatic BC patients.

\begin{tabular}{|c|c|c|c|c|c|c|c|}
\hline Reference & Patient collective & $\begin{array}{l}\text { Number } \\
\text { of } \\
\text { patients }\end{array}$ & $\begin{array}{c}\text { CTC } \\
\text { positivity }\end{array}$ & Method & $\begin{array}{l}\text { Median } \\
\text { follow-up } \\
\text { (months) }\end{array}$ & $\begin{array}{l}\text { Association } \\
\text { between } \\
\text { CTCs and } \\
\text { survival }\end{array}$ & $\begin{array}{l}\text { Association between CTCs } \\
\text { and pathological response } \\
\text { of the primary tumor to } \\
\text { neoadjuvant therapy }\end{array}$ \\
\hline $\begin{array}{l}\text { Rack et al. (13), } \\
\text { SUCCESS trial }\end{array}$ & $\begin{array}{l}\text { Stages I-III, node-positive or high risk node- } \\
\text { negative; blood sample taken after adjuvant } \\
\text { chemotherapy }\end{array}$ & 1493 & 330 (22\%) & CellSearch & 36 & DFS, OS & - \\
\hline $\begin{array}{l}\text { Riethdorf } \\
\text { et al. (34), } \\
\text { GeparQuattro trial }\end{array}$ & $\begin{array}{l}\text { High-risk non-metastatic BC after } \\
\text { neoadjuvant chemotherapy }\end{array}$ & 207 & $22(11 \%)$ & CellSearch & - & n.d. & No \\
\hline $\begin{array}{l}\text { Kasimir-Bauer } \\
\text { et al. (35) }\end{array}$ & $\begin{array}{l}\text { Neoadjuvant trial, Stages II and III, ineligible } \\
\text { for breast conserving surgery at diagnosis } \\
\text { or high-risk; blood and BM samples taken } \\
\text { before and after neoadjuvant chemotherapy }\end{array}$ & 133 & $11(8 \%)$ & AdnaTest & 52 & No & No \\
\hline Hall et al. (36) & $\begin{array}{l}\text { Triple-negative early BC after neoadjuvant } \\
\text { chemotherapy }\end{array}$ & 57 & $17(30 \%)$ & CellSearch & 30 & RFS, OS & No \\
\hline $\begin{array}{l}\text { Bidard et al. (14), } \\
\text { Pierga et al. (37) } \\
\text { REMAGUSO2 trial }\end{array}$ & $\begin{array}{l}\text { Neoadjuvant trial, Stages II and III, ineligible } \\
\text { for breast conserving surgery at diagnosis } \\
\text { or high-risk; blood sample taken after } \\
\text { neoadjuvant chemotherapy }\end{array}$ & 85 & $15(18 \%)$ & CellSearch & 70 & No & No \\
\hline
\end{tabular}

DFS, disease-free survival; OS, overall survival; RFS, relapse-free survival. 
the 36-month OS and DFS were higher in patients who were CTC-negative at both time points compared to those CTCpositive before and after chemotherapy (OS: 97.6 vs. 92.8\%; DFS: 93.9 vs. $85.9 \%$, respectively). Furthermore, presence of persistent CTCs 2 years after completion of chemotherapy in clinically disease-free patients predicted worse survival as well (33). In this context, one needs to keep in mind that CTCs represent a heterogenous population and that while systemic treatment may eradicate a large proportion of CTCs, tumor cells with enhanced resistant mechanisms may survive and lead to metastatic growth. To date, however, evidence regarding clinical relevance of specific subtypes of persistent CTCs is limited.

Furthermore, Hall et al. examined blood samples from 57 patients with triple-negative $\mathrm{BC}$ after completion of neoadjuvant therapy and found a significant correlation between CTC presence and shorter relapse-free and overall survival (36). Others reported conflicting results in the neoadjuvant setting $(14,35$, 38). Several studies aimed at exploring the interaction between CTC dynamics and pathological changes in the primary tumor during chemotherapy. Pathological complete response has been shown to predict long-term survival and is being used as an endpoint in numerous clinical trials (39). However, changes in CTCs were not associated with tumor's response to treatment in most studies; in the neoadjuvant REMAGUS02 trial, neither presence of persistent CTCs after chemotherapy nor changes in CTC status correlated with pathological complete response (37). Riethdorf et al. examined blood samples from 213 BC patients before and 207 BC patients after neoadjuvant treatment in the GeparQuattro trial (34). While CTCs could be detected in $22 \%$ of patients before start of treatment, the positivity rate decreased to $11 \%$ after chemotherapy. However, no correlation between response to therapy and CTC dynamics could be found.

In the neoadjuvant setting, achievement of pathological complete response is significantly linked to favorable survival. In case of adjuvant therapy, this simple tool for response monitoring is no longer available as systemic treatment is administered after surgery. In a study by Xenidis et al., 237 initially CTC-positive patients received either taxane-based or taxane-free adjuvant therapy (40). After a median follow-up of 71 months, patients treated with taxane-based regimen had longer DFS than those receiving taxane-free treatment. Positive effects on survival in the taxane-group were reflected by a shift toward CTC-negative status: $50 \%$ of taxane-treated patients turned CTC-negative compared to only $33 \%$ in the taxane-free arm.

\section{Therapy Choices Based on CTCs in Early BC}

Treatment decisions in non-metastatic BC are based on the characteristics of the primary tumor without considering features of MRD, although the latter is the aim of any adjuvant strategy and molecular profile of MRD may differ from the primary tumor (41). For instance, we previously reported that $71 \%$ of patients with ER-positive BC present with ER-negative DTCs in BM; the loss of hormone receptor positivity may contribute to development of endocrine resistance (42). With regard to another predictive marker, HER2, Riethdorf et al. demonstrated that in $19 \%$ of patients with HER2-negative BC HER2-positive CTCs may be detected in PB (34). Similar results were reported with respect to DTCs in BM as well $(26,34,43)$. According to current guidelines, patients with HER2-positive MRD but HER2-negative tumors are not eligible for anti-HER2targeted treatment since only histologically proven HER2 status - either in the primary tumor or in a metastatic lesion - is taken into account. Whether this undertreatment results in worse survival and, consequently, whether these patients benefit from HER2-targeted therapy, remains to be clarified. Rack et al. showed that secondary adjuvant administration of trastuzumab eliminates HER2-positive DTCs from the BM of patients with HER2-negative BC (44). The ongoing TREAT CTC trial (NCT01548677) is the first liquid biopsy-based large trial evaluating the concept of targeting chemoresistant MRD (45). Patients with CTCs persisting beyond (neo)adjuvant chemotherapy are randomized between six cycles of trastuzumab intravenously every 3 weeks vs. observation. In this trial, HER2 status of the CTCs will be assessed, but the treatment is based on the presence of CTCs and not on their HER2 status. Apart from the patients' characteristics of the pilot phase, this trial has not reported any results yet.

\section{CIRCULATING TUMOR CELLS IN METASTATIC BREAST CANCER}

\section{Prognostic Significance of CTCs in Metastatic BC}

A total of $40-80 \%$ of patients with metastatic BC present with CTCs in PB (Table 3). As demonstrated by Cristofanilli et al., CTC levels above the cutoff value of $\geq 5$ cells $/ 7.5 \mathrm{ml}$ blood at the time of diagnosis are associated with impaired clinical outcome $(46,47)$. The prognostic value of the threshold of $\geq 5$ CTCs $/ 7.5 \mathrm{ml}$ PB has been further validated by several studies and remains unchanged during the follow-up (37, 47-52). A recent pooled analysis on 1944 metastatic BC patients demonstrated the influence of CTCs on progression-free and overall survival with the highest level of evidence (53).

Next to the prognostic role of CTC status, changes in CTC counts in course of treatment have been shown to reflect therapy response: in the analysis by Hayes et al., a decrease in CTC levels under the threshold of five cells in $7.5 \mathrm{ml} \mathrm{PB}$ predicted better PFS and OS (49). Furthermore, treatment efficacy assessed by CTC evaluation might be more suitable for therapy monitoring than standard radiological imaging (48). In a prospective trial by Budd et al., CTC persistence in metastatic BC patients predicted impaired clinical outcome despite radiological therapy response (48). In this context, a simple and non-invasive blood analysis for CTCs as a "liquid biopsy" represents an attractive tool allowing a real-time monitoring of disease progression and therapy response.

Beyond CTC enumeration and monitoring of CTC levels during the therapy, characterization of these cells, especially with regard to hormone and HER2 status, has been addressed in 
TABLE 3 | Prognostic value of CTCs in metastatic breast cancer patients.

\begin{tabular}{|c|c|c|c|c|}
\hline Reference & Number of patients & Method & CTC positivity & Association between СTCs and survival \\
\hline Bidard et al. (53) & 1944 & CellSearch & $47 \%^{a}$ & PFS, OS \\
\hline Smerage et al. (54) & 564 & CellSearch & $51 \%^{a}$ & PFS, OS \\
\hline Wallwiener et al. (52) & 486 & CellSearch & $42 \%$ & PFS, OS \\
\hline Giordano et al. (51) & 517 & CellSearch & $40 \%{ }^{a}$ & PFS, OS \\
\hline Pierga et al. (55) & 267 & CellSearch & $44 \%^{a}$ & PFS, OS \\
\hline Müller et al. (56) & 254 & CellSearch AdnaTest & CSS: $50 \%{ }^{a}$ AT: $40 \%$ & CellSearch: OS AdnaTest: n.s. \\
\hline Giuliano et al. (50) & 235 & CellSearch & $40 \%^{a}$ & PFS, OS \\
\hline Nakamura et al. (57) & 107 & CellSearch & $37 \%^{a}$ & PFS \\
\hline Liu et al. (58) & 74 & CellSearch & n.s. & PFS \\
\hline Tewes et al. (59) & 42 & AdnaTest & $52 \%$ & Os \\
\hline Bidard et al. (60) & 37 & Immunocytochemistry & $41 \%$ & OS \\
\hline Nole et al. (61) & 80 & CellSearch & $61 \%$ & PFS \\
\hline Hayes et al. (49) & 177 & CellSearch & $54 \%$ & PFS, OS ${ }^{b}$ \\
\hline Budd et al. (48) & 138 & CellSearch & $43 \%$ & OS \\
\hline Cristofanilli et al. (47) & 177 & CellSearch & $49 \%$ & PFS, OS \\
\hline
\end{tabular}

PFS, progression-free survival; OS, overall survival.

${ }^{a} \geq 5$ CTCS.

${ }^{b}$ At any time during palliative treatment.

several studies on metastatic BC. According to numerous trials, the phenotype and genotype of primary tumor, metastatic lesion, and CTCs often differ (62-66). Hypothetically, CTCs represent the dominant tumor cell population in metastatic disease; therefore, their expression profile may predict therapeutic response most adequately (67). As reported to date, targeted therapy guided by phenotype of CTCs is able to eliminate persistent tumor cells from $\mathrm{PB}$ and/or $\mathrm{BM}$ of $\mathrm{BC}$ patients $(44,68,69)$. While prognostic relevance of CTC enumeration in the metastatic setting has been proven in large clinical trials, studies investigating the impact of specific phenotypes of CTCs on survival have yielded contradictory results. Wallwiener et al. evaluated HER2 status on CTCs in 107 metastatic BC patients starting a new line of therapy (65). The HER2 status of CTCs did not influence overall survival. However, patients with HER2-positive CTCs had significantly longer PFS than those with HER2-negative CTCs. In contrast, Hayashi et al. reported worse survival in patients with HER2-positive CTCs (70), and Beije et al. assessed ER and HER2 status on CTCs from $154 \mathrm{MBC}$ patients and reported that none correlated with clinical outcome (71).

Clinical significance of CTC phenotype (in particular, the HER2 status) for guiding treatment decisions and evaluating therapy response in metastatic $\mathrm{BC}$ is being currently investigated within the German DETECT trials (NCT01619111). Moreover, the possibility to provide an analysis of CTCs in metastatic BC on a DNA, RNA, and protein level including next-generation sequencing has been demonstrated by recent research $(72,73)$. CTC characterization on the molecular level might help to identify resistance mechanisms of tumor cells: a crucial step for the optimization of systemic treatment (67).

\section{CTCs as a Therapy Monitoring Tool in Metastatic BC}

While the prognostic relevance of CTC detection has been proven in large clinical trials, its clinical utility remains to be demonstrated $(13,47)$. Since CTC detection predicts impaired clinical outcome and CTC dynamics seem to reflect treatment response, a question has been raised, whether $\mathrm{MBC}$ patients can benefit from CTC-guided therapy decisions. The first large clinical trial to address this issue is the SWOG S0500 study (NCT00382018). In this randomized Phase III trial, metastatic BC patients with persistent high levels of CTCs after first cycle of initial chemotherapy ( $\geq 5 / 7.5 \mathrm{ml}$ of blood) were randomized to switch the therapy or to maintain the current treatment until the clinical evidence of progression (54). While the strong prognostic power of CTCs has been confirmed by this study, treatment change based on CTC persistence did not improve progression-free survival or overall survival in these patients. The clinical outcome was poorest in patients with persistently elevated CTC levels, and these patients might represent a chemoresistant population that requires alternative treatment approaches (54). Furthermore, a currently ongoing study on therapy guidance based on CTC dynamics in metastatic BC is the CirCe01 by Institut Curie, France (NCT01349842). In this multicentre randomized Phase III study, therapy response in CTC-positive patients with disease progression after two lines of chemotherapy is being assessed by clinical tests and radiological imaging or by CTC enumeration. Patients without a significant decrease in CTC levels after first cycle of new chemotherapy will be switched to an alternative regime, which will also be evaluated by CTCs. First results of CirCe01 are expected in 2018 (74). Both studies attempt to demonstrate that patients with persistently elevated CTCs under cytotoxic treatment should be switched off this regimen early in order to avoid inefficient and toxic chemotherapies.

\section{Therapy Choices Based on CTCs in Metastatic BC}

The question whether the choice of systemic treatment in hormone receptor-positive HER2-negative metastatic BC patients might be driven by CTC levels has been raised by the STIC-CTC trial (NCT01710605, Institut Curie, France). In this 
TABLE 4 | Current studies on therapeutic utility of CTCs in metastatic breast cancer.

\begin{tabular}{|c|c|c|c|c|}
\hline Trial & Status & Condition & Intervention & $\begin{array}{l}\text { Primary } \\
\text { endpoint }\end{array}$ \\
\hline $\begin{array}{l}\text { SWOG S0500 NCT00382018 } \\
\text { (Phase III) }\end{array}$ & Active, not recruiting & $\begin{array}{l}\text { CTC persistence under } \\
\text { chemotherapy }\end{array}$ & $\begin{array}{l}\text { Treatment choice based on clinical and radiological } \\
\text { criteria vs. CTC-guided treatment choice }\end{array}$ & os \\
\hline CirCe01 NCT01349842 (Phase III) & Recruiting & $\begin{array}{l}\text { CTC persistence under } \\
\text { chemotherapy }\end{array}$ & $\begin{array}{l}\text { Treatment choice based on clinical and radiological } \\
\text { criteria vs. CTC-guided treatment choice }\end{array}$ & OS \\
\hline STIC-CTC NCT01710605 (Phase III) & Recruiting & $\mathrm{HR}+/ \mathrm{HER} 2-\mathrm{MBC}$ & $\begin{array}{l}\text { Clinicians choice vs. CTC-guided choice between } \\
\text { chemotherapy and endocrine therapy }\end{array}$ & PFS \\
\hline DETECT III NCT01619111 (Phase III) & Recruiting & $\begin{array}{l}\text { HER2-negative metastatic BC } \\
\text { with HER2-positive CTCs }\end{array}$ & Standard therapy \pm lapatinib & CTC clearance \\
\hline DETECT IV NCT02035813 (Phase II) & Recruiting & $\begin{array}{l}\text { HER2-negative metastatic BC } \\
\text { with HER2-negative CTCs }\end{array}$ & $\begin{array}{l}\text { Endocrine therapy + everolimus (DETECT IV a) or } \\
\text { eribulin (DETECT IV b) }\end{array}$ & PFS \\
\hline NCT01975142 (Phase II) & Recruiting & $\begin{array}{l}\text { HER2-negative metastatic BC } \\
\text { with HER2-positive CTCs }\end{array}$ & T-DM1 & $\begin{array}{l}\text { Tumor response } \\
\text { rate }\end{array}$ \\
\hline
\end{tabular}

randomized Phase III trial, the treatment decision will be left at the discretion of the clinicians or according to the number of CTCs in PB: endocrine therapy in case of a CTC count $<5$ CTCs/7.5 ml PB or chemotherapy in case of a CTC count $\geq 5 / 7.5 \mathrm{ml} \mathrm{PB}$.

The worldwide largest trial for therapy guidance according to the CTC status and/or CTC phenotype in metastatic BC patients is the DETECT study concept. In this multicenter study, women with HER2-negative metastatic disease and at least one HER2positiveCTCare enrolled in theDETECTIIItrial(NCT01619111), and women with HER2-negative BC (hormone receptor-positive or triple-negative) and exclusively HER2-negative CTCs are eligible for the DETECT IV trial (NCT02035813). The recently initiated DETECT V/CHEVENDO trial (Chemo vs. Endo, NCT02344472) completes the DETECT study program with a clinical trial for HER2-positive hormone receptor-positive metastatic BC patients. In the DETECT III trial, patients are randomized to standard systemic treatment of physician's choice \pm additional therapy with lapatinib. In the DETECT IV trial, patients with hormone receptor-positive tumors are treated with endocrine therapy plus everolimus, as a study medication, whereas patients with hormone receptor-positive tumors and indication for chemotherapy as well as patients with triple-negative tumors are treated with eribulin. Metastatic BC patients with HER2-positive hormone receptor-positive tumors are treated with dual HER2-targeted therapy (pertuzumab/trastuzumab) either in combination with chemotherapy or endocrine therapy within the DETECT V/CHEVENDO trial. In DETECT III and DETECT IV, presence of CTCs is mandatory for study inclusion and changes in CTC levels during the treatment are evaluated by repeated blood sampling during the therapy. The accompanying translational research projects of all DETECT studies try to generate additional knowledge of CTCs, their biology and their role in predicting treatment response using methods like single cell analysis, SNaP-Shot technology and next-generation sequencing. This may help to identify new treatment targets and provide more individualized therapy and finally further clarify the clinical value of CTCs in metastatic BC. Currently, ongoing trials on therapeutic utility of CTCs in metastatic BC are summarized in Table 4.
TABLE 5 | Potential future applications of CTC detection and characterization.

\begin{tabular}{|c|c|}
\hline Early BC & Metastatic BC \\
\hline $\begin{array}{l}\text { - } \text { CTC detection might improve } \\
\text { prognostication and help to identify } \\
\text { patients in need of aggressive } \\
\text { therapy and/or bisphosphonates } \\
\text { - CTC persistence might serve as } \\
\text { stratifying parameter to select } \\
\text { patients who benefit most from } \\
\text { extended endocrine treatment } \\
\text { - Patients with CTC persistence } \\
\text { beyond adjuvant chemotherapy } \\
\text { might potentially benefit from } \\
\text { secondary adjuvant treatment } \\
\text { - Evaluation of predictive markers } \\
\text { on CTCs might serve as basis for } \\
\text { treatment decisions: e.g., patients } \\
\text { with HER2-negative primary tumor } \\
\text { but HER2-positive CTCs might } \\
\text { benefit from HER2-targeted therapy }\end{array}$ & $\begin{array}{l}\text { - Detection of high CTC levels } \\
\text { and thus worse prognosis might } \\
\text { become a valuable information for } \\
\text { improved care planning in palliative } \\
\text { setting } \\
\text { - CTC detection after start of a } \\
\text { new line of chemotherapy helps } \\
\text { to predict response to treatment } \\
\text { early; patients with high CTC } \\
\text { levels might either be switched to } \\
\text { another therapy approach (benefit } \\
\text { so far not confirmed in trials) or } \\
\text { to best supportive care to avoid } \\
\text { unnecessary toxicity } \\
\text { - Evaluation of CTCs may serve as } \\
\text { a liquid biopsy and thus render } \\
\text { invasive biopsy of metastasis } \\
\text { unnecessary; serial CTC } \\
\text { measurements might provide } \\
\text { continuous insight into current } \\
\text { status of the disease }\end{array}$ \\
\hline
\end{tabular}

\section{CONCLUSION}

Evaluation of CTCs is one of the most promising biomarkers in solid tumors. In BC, presence of CTCs is an independent predictor of poor clinical outcome in both early and metastatic setting. Numerous potential clinical applications have been proposed and are currently being investigated (Table 5). In case of early $\mathrm{BC}$, the assessment of therapeutic targets is so far restricted to the primary tumor despite increasing evidence of significant discordances between primary tumor and MRD, especially with respect to hormone receptor and HER2 status. Since CTCs might reflect certain, hypothetically most aggressive, subpopulations of the tumor, molecular analysis of these cells and detection of their persistence might identify patients in need of additional or targeted treatment.

In metastatic disease, one of the most exciting possibilities is the concept of CTC-guided treatment. Two settings are currently 
under investigation: first, since several studies have shown that persistently high CTC levels under systemic therapy reflect disease progression sooner than imaging-based monitoring, CTC monitoring might help to identify patients who do not benefit from cytotoxic treatment. However, since an early switch to another chemotherapy regimen in case of high CTC levels after the first cycle of palliative treatment has not shown any survival benefit, it remains to be clarified which therapy options should be favored in such case. Second, a number of clinical trials aim

\section{REFERENCES}

1. Ashworth TR. A case of cancer in which cells similar to those in tumors were seen in the blood after death. Aust Med J (1869) 14:146-9.

2. Paget S. Distribution of secondary growths in cancer of the breast. Lancet (1889) 1:571. doi:10.1016/S0140-6736(00)49915-0

3. Braun S, Vogl FD, Naume B, Janni W, Osborne MP, Coombes RC, et al. A pooled analysis of bone marrow micrometastasis in breast cancer. $N$ Engl J Med (2005) 353(8):793-802. doi:10.1056/NEJMoa050434

4. Banys M, Hartkopf AD, Krawczyk N, Kaiser T, Meier-Stiegen F, Fehm T, et al. Dormancy in breast cancer. Breast Cancer (Dove Med Press) (2012) 4:183-91. doi:10.2147/BCTT.S26431

5. Pantel K, Brakenhoff RH. Dissecting the metastatic cascade. Nat Rev Cancer (2004) 4(6):448-56. doi:10.1038/nrc1370

6. Mohme M, Riethdorf S, Pantel K. Circulating and disseminated tumour cells - mechanisms of immune surveillance and escape. Nat Rev Clin Oncol (2016). doi:10.1038/nrclinonc.2016.144

7. Baccelli I, Schneeweiss A, Riethdorf S, Stenzinger A, Schillert A, Vogel V, et al. Identification of a population of blood circulating tumor cells from breast cancer patients that initiates metastasis in a xenograft assay. Nat Biotechnol (2013) 31(6):539-44. doi:10.1038/nbt.2576

8. Steinert G, Scholch S, Niemietz T, Iwata N, Garcia SA, Behrens B, et al. Immune escape and survival mechanisms in circulating tumor cells of colorectal cancer. Cancer Res (2014) 74(6):1694-704. doi:10.1158/0008-5472.CAN-13-1885

9. Nagahara M, Mimori K, Kataoka A, Ishii H, Tanaka F, Nakagawa T, et al. Correlated expression of CD47 and SIRPA in bone marrow and in peripheral blood predicts recurrence in breast cancer patients. Clin Cancer Res (2010) 16(18):4625-35. doi:10.1158/1078-0432.CCR-10-0349

10. Pantel K, Schlimok G, Kutter D, Schaller G, Genz T, Wiebecke B, et al. Frequent down-regulation of major histocompatibility class I antigen expression on individual micrometastatic carcinoma cells. Cancer Res (1991) 51(17):4712-5.

11. Kaplan RN, Riba RD, Zacharoulis S, Bramley AH, Vincent L, Costa C, et al. VEGFR1-positive haematopoietic bone marrow progenitors initiate the pre-metastatic niche. Nature (2005) 438(7069):820-7. doi:10.1038/ nature04186

12. Olkhanud PB, Baatar D, Bodogai M, Hakim F, Gress R, Anderson RL, et al. Breast cancer lung metastasis requires expression of chemokine receptor CCR4 and regulatory T cells. Cancer Res (2009) 69(14):5996-6004. doi:10.1158/0008-5472.CAN-08-4619

13. Rack B, Schindlbeck C, Juckstock J, Andergassen U, Hepp P, Zwingers T, et al. Circulating tumor cells predict survival in early average-to-high risk breast cancer patients. J Natl Cancer Inst (2014) 106(5). doi:10.1093/jnci/dju066

14. Bidard FC, Belin L, Delaloge S, Lerebours F, Ngo C, Reyal F, et al. Timedependent prognostic impact of circulating tumor cells detection in non-metastatic breast cancer: 70-month analysis of the REMAGUS02 study. Int J Breast Cancer (2013) 2013:130470. doi:10.1155/2013/130470

15. Franken B, de Groot MR, Mastboom WJ, Vermes I, van der Palen J, Tibbe AG, et al. Circulating tumor cells, disease recurrence and survival in newly diagnosed breast cancer. Breast Cancer Res (2012) 14(5):R133. doi:10.1186/ bcr3333

16. Janni WJ, Rack B, Terstappen LW, Pierga JY, Taran FA, Fehm T, et al. Pooled analysis of the prognostic relevance of circulating tumor cells in primary breast cancer. Clin Cancer Res (2016) 22(10):2583-93. doi:10.1158/1078-0432. CCR-15-1603 at clarifying whether metastasized patients benefit from targeted therapy based on the molecular profile of CTCs rather than that of the primary tumor.

\section{AUTHOR CONTRIBUTIONS}

MB-P, NK, and TF contributed significantly to this manuscript. All the authors read and approved the manuscript.

17. Ignatiadis M, Xenidis N, Perraki M, Apostolaki S, Politaki E, Kafousi M, et al. Different prognostic value of cytokeratin-19 mRNA positive circulating tumor cells according to estrogen receptor and HER2 status in early-stage breast cancer. J Clin Oncol (2007) 25(33):5194-202. doi:10.1200/JCO.2007. 11.7762

18. Ignatiadis M, Perraki M, Apostolaki S, Politaki E, Xenidis N, Kafousi M, et al. Molecular detection and prognostic value of circulating cytokeratin-19 messenger RNA-positive and HER2 messenger RNA-positive cells in the peripheral blood of women with early-stage breast cancer. Clin Breast Cancer (2007) 7(11):883-9. doi:10.3816/CBC.2007.n.054

19. Hwang SB, Bae JW, Lee HY, Kim HY. Circulating tumor cells detected by RT-PCR for CK-20 before surgery indicate worse prognostic impact in triple-negative and HER2 subtype breast cancer. J Breast Cancer (2012) 15(1):34-42. doi:10.4048/jbc.2012.15.1.34

20. Karhade M, Hall C, Mishra P, Anderson A, Kuerer H, Bedrosian I, et al. Circulating tumor cells in non-metastatic triple-negative breast cancer. Breast Cancer Res Treat (2014) 147(2):325-33. doi:10.1007/s10549-014-3103-7

21. Banys-Paluchowski M, Schneck H, Blassl C, Schultz S, Meier-Stiegen F, Niederacher D, et al. Prognostic relevance of circulating tumor cells in molecular subtypes of breast cancer. Geburtshilfe Frauenheilkd (2015) 75(3):232-7. doi:10.1055/s-0035-1545788

22. Lim E, Metzger-Filho O, Winer EP. The natural history of hormone receptor-positive breast cancer. Oncology (Williston Park) (2012) 26(8):688-94.

23. Lucci A, Hall CS, Lodhi AK, Bhattacharyya A, Anderson AE, Xiao L, et al. Circulating tumour cells in non-metastatic breast cancer: a prospective study. Lancet Oncol (2012) 13(7):688-95. doi:10.1016/S1470-2045(12)70209-7

24. Molloy TJ, Bosma AJ, Baumbusch LO, Synnestvedt M, Borgen E, Russnes HG, et al. The prognostic significance of tumour cell detection in the peripheral blood versus the bone marrow in 733 early-stage breast cancer patients. Breast Cancer Res (2011) 13(3):R61. doi:10.1186/bcr2898

25. Kuniyoshi RK, de Sousa Gehrke F, Alves BC, Vilas-Boas V, Colo AE, Sousa N, et al. Gene profiling and circulating tumor cells as biomarker to prognostic of patients with locoregional breast cancer. Tumour Biol (2015) 36(10):8075-83. doi:10.1007/s13277-015-3529-5

26. Fehm T, Hoffmann O, Aktas B, Becker S, Solomayer EF, Wallwiener D, et al. Detection and characterization of circulating tumor cells in blood of primary breast cancer patients by RT-PCR and comparison to status of bone marrow disseminated cells. Breast Cancer Res (2009) 11(4):R59. doi:10.1186/bcr2349

27. Wulfing $\mathrm{P}$, Borchard J, Buerger H, Heidl S, Zanker KS, Kiesel L, et al. HER2-positive circulating tumor cells indicate poor clinical outcome in stage I to III breast cancer patients. Clin Cancer Res (2006) 12(6):1715-20. doi:10.1158/1078-0432.CCR-05-2087

28. Kasimir-Bauer S, Reiter K, Aktas B, Bittner AK, Weber S, Keller T, et al. Different prognostic value of circulating and disseminated tumor cells in primary breast cancer: influence of bisphosphonate intake? Sci Rep (2016) 6:26355. doi:10.1038/srep26355

29. Schindlbeck C, Andergassen U, Hofmann S, Juckstock J, Jeschke U, Sommer H, et al. Comparison of circulating tumor cells (CTC) in peripheral blood and disseminated tumor cells in the bone marrow (DTC-BM) of breast cancer patients. J Cancer Res Clin Oncol (2013) 139(6):1055-62. doi:10.1007/ s00432-013-1418-0

30. Hartkopf AD, Stefanescu D, Wallwiener M, Hahn M, Becker S, Solomayer EF, et al. Tumor cell dissemination to the bone marrow and blood is associated with poor outcome in patients with metastatic breast cancer. Breast Cancer Res Treat (2014) 147(2):345-51. doi:10.1007/s10549-014-3113-5 
31. Slade MJ, Payne R, Riethdorf S, Ward B, Zaidi SA, Stebbing J, et al. Comparison of bone marrow, disseminated tumour cells and blood-circulating tumour cells in breast cancer patients after primary treatment. Br J Cancer (2009) 100(1):160-6. doi:10.1038/sj.bjc.6604773

32. Janni W, Vogl FD, Wiedswang G, Synnestvedt M, Fehm T, Juckstock J, et al. Persistence of disseminated tumor cells in the bone marrow of breast cancer patients predicts increased risk for relapse - a European pooled analysis. Clin Cancer Res (2011) 17(9):2967-76. doi:10.1158/1078-0432.CCR-10-2515

33. Janni W, Rack B, Fasching P, Haeberle L, Friedl T, Tesch H, et al. Persistence of circulating tumor cells in high risk early breast cancer patients during follow-up care suggests poor prognosis - results from the adjuvant SUCCESS A trial. 2015 San Antonio Breast Cancer Symposium, S2-03. San Antonio, TX (2015).

34. Riethdorf S, Muller V, Zhang L, Rau T, Loibl S, Komor M, et al. Detection and HER2 expression of circulating tumor cells: prospective monitoring in breast cancer patients treated in the neoadjuvant GeparQuattro trial. Clin Cancer Res (2010) 16(9):2634-45. doi:10.1158/1078-0432.CCR-09-2042

35. Kasimir-Bauer S, Bittner AK, Konig L, Reiter K, Keller T, Kimmig R, et al. Does primary neoadjuvant systemic therapy eradicate minimal residual disease? Analysis of disseminated and circulating tumor cells before and after therapy. Breast Cancer Res (2016) 18(1):20. doi:10.1186/s13058-016-0679-3

36. Hall C, Karhade M, Laubacher B, Anderson A, Kuerer H, DeSynder S, et al. Circulating tumor cells after neoadjuvant chemotherapy in stage I-III triple-negative breast cancer. Ann Surg Oncol (2015) 22(Suppl 3):S552-8. doi:10.1245/s10434-015-4600-6

37. Pierga JY, Bidard FC, Mathiot C, Brain E, Delaloge S, Giachetti S, et al. Circulating tumor cell detection predicts early metastatic relapse after neoadjuvant chemotherapy in large operable and locally advanced breast cancer in a phase II randomized trial. Clin Cancer Res (2008) 14(21):7004-10. doi:10.1158/1078-0432.CCR-08-0030

38. Bidard FC, Mathiot C, Delaloge S, Brain E, Giachetti S, de Cremoux P, et al. Single circulating tumor cell detection and overall survival in nonmetastatic breast cancer. Ann Oncol (2010) 21(4):729-33. doi:10.1093/annonc/mdp391

39. Cortazar P, Zhang L, Untch M, Mehta K, Costantino JP, Wolmark N, et al. Pathological complete response and long-term clinical benefit in breast cancer: the CTNeoBC pooled analysis. Lancet (2014) 384(9938):164-72. doi:10.1016/S0140-6736(13)62422-8

40. Xenidis N, Perraki M, Apostolaki S, Agelaki S, Kalbakis K, Vardakis N, et al. Differential effect of adjuvant taxane-based and taxane-free chemotherapy regimens on the CK-19 mRNA-positive circulating tumour cells in patients with early breast cancer. Br J Cancer (2013) 108(3):549-56. doi:10.1038/ bjc.2012.597

41. Banys M, Muller V, Melcher C, Aktas B, Kasimir-Bauer S, Hagenbeck C, et al. Circulating tumor cells in breast cancer. Clin Chim Acta (2013) 423:39-45. doi:10.1016/j.cca.2013.03.029

42. Fehm T, Krawczyk N, Solomayer EF, Becker-Pergola G, Durr-Storzer S, Neubauer $\mathrm{H}$, et al. ERalpha-status of disseminated tumour cells in bone marrow of primary breast cancer patients. Breast Cancer Res (2008) 10(5):R76. doi:10.1186/bcr2143

43. Krawczyk N, Banys M, Neubauer H, Solomayer EF, Gall C, Hahn M, et al. HER2 status on persistent disseminated tumor cells after adjuvant therapy may differ from initial HER2 status on primary tumor. Anticancer Res (2009) 29(10):4019-24.

44. Rack B, Juckstock J, Gunthner-Biller M, Andergassen U, Neugebauer J, Hepp P, et al. Trastuzumab clears HER2/neu-positive isolated tumor cells from bone marrow in primary breast cancer patients. Arch Gynecol Obstet (2012) 285(2):485-92. doi:10.1007/s00404-011-1954-2

45. Ignatiadis M, Rack B, Rothe F, Riethdorf S, Decraene C, Bonnefoi H, et al. Liquid biopsy-based clinical research in early breast cancer: the EORTC 90091-10093 Treat CTC Trial. Eur J Cancer (2016) 63:97-104. doi:10.1016/ j.ejca.2016.04.024

46. Cristofanilli M, Hayes DF, Budd GT, Ellis MJ, Stopeck A, Reuben JM, et al. Circulating tumor cells: a novel prognostic factor for newly diagnosed metastatic breast cancer. J Clin Oncol (2005) 23(7):1420-30. doi:10.1200/ JCO.2005.08.140

47. Cristofanilli M, Budd GT, Ellis MJ, Stopeck A, Matera J, Miller MC, et al. Circulating tumor cells, disease progression, and survival in metastatic breast cancer. N Engl J Med (2004) 351(8):781-91. doi:10.1056/NEJMoa040766
48. Budd GT, Cristofanilli M, Ellis MJ, Stopeck A, Borden E, Miller MC, et al. Circulating tumor cells versus imaging - predicting overall survival in metastatic breast cancer. Clin Cancer Res (2006) 12(21):6403-9. doi:10.1158/10780432.CCR-05-1769

49. Hayes DF, Cristofanilli M, Budd GT, Ellis MJ, Stopeck A, Miller MC, et al. Circulating tumor cells at each follow-up time point during therapy of metastatic breast cancer patients predict progression-free and overall survival. Clin Cancer Res (2006) 12(14 Pt 1):4218-24. doi:10.1158/1078-0432.CCR-05-2821

50. Giuliano M, Giordano A, Jackson S, Hess KR, De Giorgi U, Mego M, et al. Circulating tumor cells as prognostic and predictive markers in metastatic breast cancer patients receiving first-line systemic treatment. Breast Cancer Res (2011) 13(3):R67. doi:10.1186/bcr2907

51. Giordano A, Giuliano M, De Laurentiis M, Arpino G, Jackson S, Handy BC, et al. Circulating tumor cells in immunohistochemical subtypes of metastatic breast cancer: lack of prediction in HER2-positive disease treated with targeted therapy. Ann Oncol (2012) 23(5):1144-50. doi:10.1093/annonc/mdr434

52. Wallwiener M, Hartkopf AD, Baccelli I, Riethdorf S, Schott S, Pantel K, et al. The prognostic impact of circulating tumor cells in subtypes of metastatic breast cancer. Breast Cancer Res Treat (2013) 137(2):503-10. doi:10.1007/ s10549-012-2382-0

53. Bidard FC, Peeters DJ, Fehm T, Nole F, Gisbert-Criado R, Mavroudis D, et al. Clinical validity of circulating tumour cells in patients with metastatic breast cancer: a pooled analysis of individual patient data. Lancet Oncol (2014) 15(4):406-14. doi:10.1016/S1470-2045(14)70069-5

54. Smerage JB, Barlow WE, Hortobagyi GN, Winer EP, Leyland-Jones B, Srkalovic G, et al. Circulating tumor cells and response to chemotherapy in metastatic breast cancer: SWOG S0500. J Clin Oncol (2014) 32(31):3483-9. doi:10.1200/JCO.2014.56.2561

55. Pierga JY, Hajage D, Bachelot T, Delaloge S, Brain E, Campone M, et al. High independent prognostic and predictive value of circulating tumor cells compared with serum tumor markers in a large prospective trial in firstline chemotherapy for metastatic breast cancer patients. Ann Oncol (2012) 23(3):618-24. doi:10.1093/annonc/mdr263

56. Müller V, Riethdorf S, Rack B, Janni W, Fasching PA, Solomayer E, et al. Prognostic impact of circulating tumor cells assessed with the CellSearch System and AdnaTest Breast in metastatic breast cancer patients: the DETECT study. Breast Cancer Res (2012) 14(4):R118. doi:10.1186/bcr3243

57. Nakamura S, Yagata H, Ohno S, Yamaguchi H, Iwata H, Tsunoda N, et al. Multi-center study evaluating circulating tumor cells as a surrogate for response to treatment and overall survival in metastatic breast cancer. Breast Cancer (2010) 17(3):199-204. doi:10.1007/s12282-009-0139-3

58. Liu MC, Shields PG, Warren RD, Cohen P, Wilkinson M, Ottaviano YL, et al. Circulating tumor cells: a useful predictor of treatment efficacy in metastatic breast cancer. JClin Oncol (2009) 27(31):5153-9. doi:10.1200/ JCO.2008.20.6664

59. Tewes M, Aktas B, Welt A, Mueller S, Hauch S, Kimmig R, et al. Molecular profiling and predictive value of circulating tumor cells in patients with metastatic breast cancer: an option for monitoring response to breast cancer related therapies. Breast Cancer Res Treat (2009) 115(3):581-90. doi:10.1007/ s10549-008-0143-x

60. Bidard FC, Vincent-Salomon A, Sigal-Zafrani B, Dieras V, Mathiot C, Mignot L, et al. Prognosis of women with stage IV breast cancer depends on detection of circulating tumor cells rather than disseminated tumor cells. Ann Oncol (2008) 19(3):496-500. doi:10.1093/annonc/mdm507

61. Nole F, Munzone E, Zorzino L, Minchella I, Salvatici M, Botteri E, et al. Variation of circulating tumor cell levels during treatment of metastatic breast cancer: prognostic and therapeutic implications. Ann Oncol (2008) 19(5):891-7. doi:10.1093/annonc/mdm558

62. Kalinsky K, Mayer JA, Xu X, Pham T, Wong KL, Villarin E, et al. Correlation of hormone receptor status between circulating tumor cells, primary tumor, and metastasis in breast cancer patients. Clin Transl Oncol (2015) 17(7):539-46. doi:10.1007/s12094-015-1275-1

63. Babayan A, Hannemann J, Spotter J, Muller V, Pantel K, Joosse SA. Heterogeneity of estrogen receptor expression in circulating tumor cells from metastatic breast cancer patients. PLoS One (2013) 8(9):e75038. doi:10.1371/ journal.pone. 0075038

64. Pestrin M, Bessi S, Galardi F, Truglia M, Biggeri A, Biagioni C, et al. Correlation of HER2 status between primary tumors and corresponding circulating 
tumor cells in advanced breast cancer patients. Breast Cancer Res Treat (2009) 118(3):523-30. doi:10.1007/s10549-009-0461-7

65. Wallwiener M, Hartkopf AD, Riethdorf S, Nees J, Sprick MR, Schonfisch B, et al. The impact of HER2 phenotype of circulating tumor cells in metastatic breast cancer: a retrospective study in 107 patients. BMC Cancer (2015) 15:403. doi:10.1186/s12885-015-1423-6

66. Fehm T, Muller V, Aktas B, Janni W, Schneeweiss A, Stickeler E, et al. HER2 status of circulating tumor cells in patients with metastatic breast cancer: a prospective, multicenter trial. Breast Cancer Res Treat (2010) 124(2):403-12. doi:10.1007/s10549-010-1163-x

67. Pantel K, Alix-Panabieres C. Real-time liquid biopsy in cancer patients: fact or fiction? Cancer Res (2013) 73(21):6384-8. doi:10.1158/0008-5472. CAN-13-2030

68. Bernhard H, Neudorfer J, Gebhard K, Conrad H, Hermann C, Nahrig J, et al. Adoptive transfer of autologous, HER2-specific, cytotoxic T lymphocytes for the treatment of HER2-overexpressing breast cancer. Cancer Immunol Immunother (2008) 57(2):271-80. doi:10.1007/s00262-007-0355-7

69. Bozionellou V, Mavroudis D, Perraki M, Papadopoulos S, Apostolaki S, Stathopoulos E, et al. Trastuzumab administration can effectively target chemotherapy-resistant cytokeratin-19 messenger RNA-positive tumor cells in the peripheral blood and bone marrow of patients with breast cancer. Clin Cancer Res (2004) 10(24):8185-94. doi:10.1158/1078-0432. CCR-03-0094

70. Hayashi N, Nakamura S, Tokuda Y, Shimoda Y, Yagata H, Yoshida A, et al. Prognostic value of HER2-positive circulating tumor cells in patients with metastatic breast cancer. Int J Clin Oncol (2012) 17(2):96-104. doi:10.1007/ s10147-011-0260-0
71. Beije N, Onstenk W, Kraan J, Sieuwerts AM, Hamberg P, Dirix LY, et al. Prognostic impact of HER2 and ER status of circulating tumor cells in metastatic breast cancer patients with a HER2-negative primary tumor. Neoplasia (2016) 18(11):647-53. doi:10.1016/j.neo.2016.08.007

72. De Luca F, Rotunno G, Salvianti F, Galardi F, Pestrin M, Gabellini S, et al. Mutational analysis of single circulating tumor cells by next generation sequencing in metastatic breast cancer. Oncotarget (2016) 7(18):26107-19. doi:10.18632/oncotarget.8431

73. Heitzer E, Auer M, Gasch C, Pichler M, Ulz P, Hoffmann EM, et al. Complex tumor genomes inferred from single circulating tumor cells by array-CGH and next-generation sequencing. Cancer Res (2013) 73(10):2965-75. doi:10.1158/0008-5472.CAN-12-4140

74. Bidard FC, Fehm T, Ignatiadis M, Smerage JB, Alix-Panabieres C, Janni W, et al. Clinical application of circulating tumor cells in breast cancer: overview of the current interventional trials. Cancer Metastasis Rev (2013) 32(1-2):179-88. doi:10.1007/s10555-012-9398-0

Conflict of Interest Statement: The authors declare that the research was conducted in the absence of any commercial or financial relationships that could be construed as a potential conflict of interest.

Copyright (c) 2016 Banys-Paluchowski, Krawczyk and Fehm. This is an open-access article distributed under the terms of the Creative Commons Attribution License (CC $B Y)$. The use, distribution or reproduction in other forums is permitted, provided the original author(s) or licensor are credited and that the original publication in this journal is cited, in accordance with accepted academic practice. No use, distribution or reproduction is permitted which does not comply with these terms. 